\title{
Paula Greenham
}

E: paulagreenham@gmail.com T: +44 7711106503

W: www.linkedin.com/in/paula-greenham-2a558450 W: www.bcig.org.uk
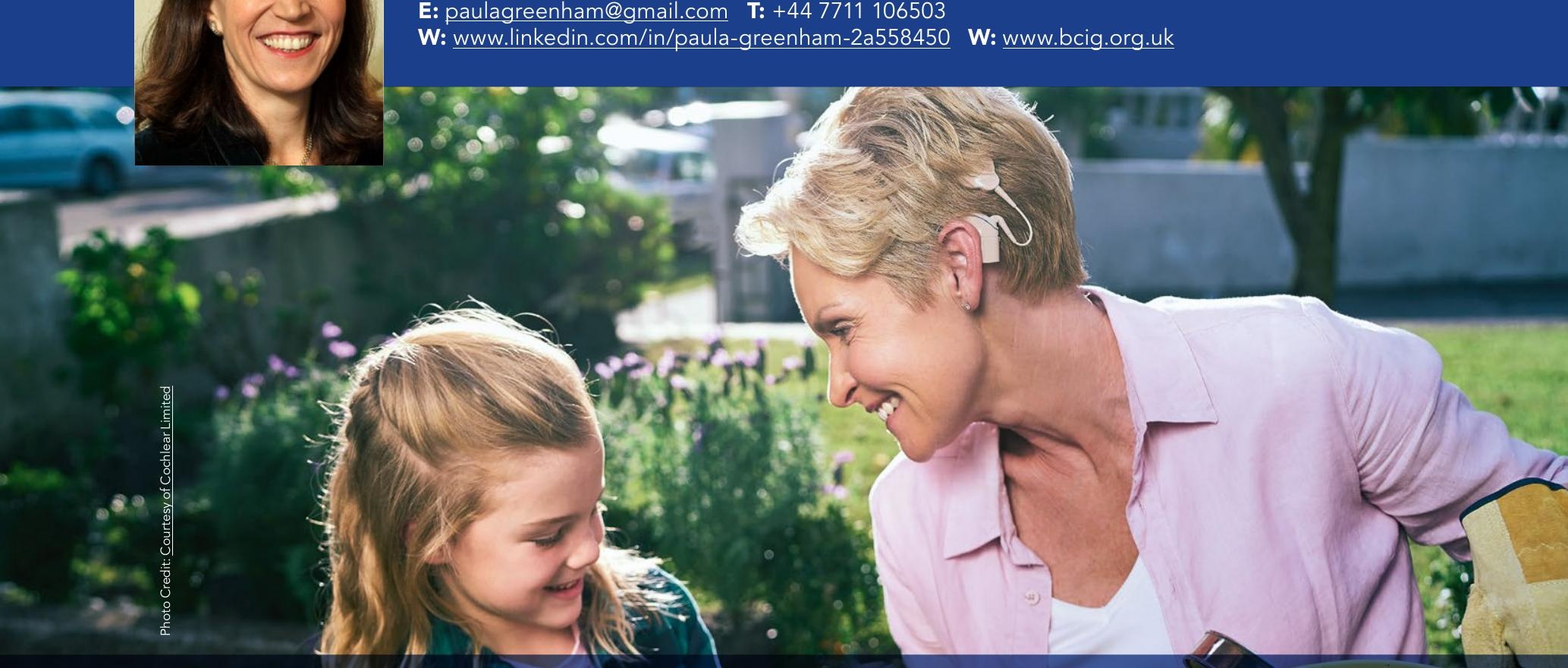

\section{Hearing loss: who gains the most from cochlear implants?}

\section{Research Objectives}

Paula Greenham studies health utility gains due to cochlear implantation.

\section{Detail}

\section{Address}

Greenham Research Consulting Ltd

Oxfordshire

UK

\section{Bio}

Paula Greenham has worked with cochlear implants for 25 years, both commercially and for the UK's National Health Service. As director of Greenham Research Consulting, she provides scientific and writing support for a range of studies and projects, and is passionate about raising public and professional awareness of implantable hearing technologies.

\section{Funding}

This work was funded by Cochlear Europe Limited.

\section{Collaborators}

- Lida Müller (Cochlear Implant Unit, Tygerberg Hospital, South Africa)

- Petra Graham (Centre for Economic Impacts of Genomic Medicine and Department of Mathematics and Statistics, Macquarie University, Australia)

- Jasmin Kaur and Josie Wyss (Cochlear AG, Basel,

Switzerland)

- Chris J James (Cochlear France SAS,

Toulouse, France)

\section{References}

Muller, L, Graham, P, Kaur, J, et al, (2020) Factors contributing to clinically important health utility gains in cochlear implant recipients. European Archives of OtoRhino-Laryngology, 0123456789. doi.org/10.1007/s00405020-06589-1

Lenarz, T, Muller, L, Zerniejewska-Wolska, CW, et al, (2017) Patient-Related Benefits for Adults with Cochlear Implantation: A Multicultural Longitudinal Observational Study. Audiology \& Neurology, 22, 61-73. doi. org/10.1159/000477533

\section{Personal Response}

\section{Do you think the predicting factors for improved health utility score change depending on the country and its socioeconomic status?}

$\boldsymbol{U}$ No. Struggling to hear on the phone even with a hearing aid is a universal indicator that a cochlear implant (Cl) may be required. Individuals with better hearing can also benefit from a $\mathrm{Cl}$, but only those in better-resourced countries tend to have access to them. 
Health \& Medicine | Paula Greenham

\section{Hearing loss}

Who gains the most from cochlear implants?

Hearing loss can cause severe disabilities and impair daily life. Cochlear implants may be an option for those who experience extreme deafness, but there are long walling lists for potential recipients in countries with limited healthcare options. Paula Greenham of Greenham Research Consulting has investigated what factors are most likely to result in improved quality or life for whividuals requing a cochlear implant.

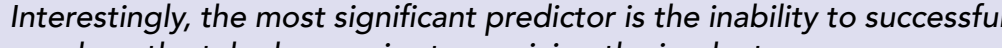

The ability to hear is arguably the most crucial sense for people's
happiness: chatting with family and friends, listening to the springtime melody of bird song or finally going to see your all-time favourite band live. It is a sense that a lot of us take for granted. Virtually everyone has experienced the loud ringing and muffled hearing in their ears after listening to something too loud and jus assumed it would wear off in time. But foring loss can oc or a number of reasons - listenin to loud sounds for too long, ageing, certain infections such meningitis, or for unlucky genetics. Loss of hearing is no at are the options for

\section{HW DO WE HEAR?}

Before we discuss the treatment options, it is important to understand how we hear. The outer ear, which we can all see, is cup shaped which allows it to gather sounds from the environment that are then directed down the ear canal. Sound travels dow the canal hrough an air cavity before reaching the eardrum. The sound wave which, in turns to a the three bones of the middle cer: the hammer, the anvil, and the stivup. The vibration is passed on to the inner - a snail-shaped structure consisting of fluid-filled chambers called the cochlea. Hair cells which act as
sensors line the cochlea and into an electrical
in impulse that can be

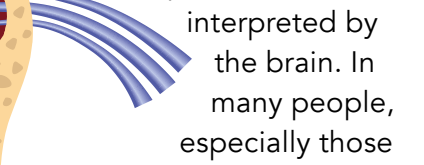
many people ho lose their hearing due to age, hearing loss is caused by damage these hair cells. The pulse travels alon auditory brainstem to the brain. Here, it ascends through different structures in the brain, allowing us to convert the vibrations and, ultimately, speech.

COCHLEAR IMPLANTS AND

\section{QUALITY OF LIFE}

A cochlear implant is an option for

hearing loss or are deaf. It's important

not to confuse a cochlear implant

with a hearing aid, which amplifies

sound before it reaches the ear

drum. A cochlear implant bypasses

the damaged ear and delivers the

sound directly to the hearing nerve.

It is an electronic device with two

separate parts, one which sits behind

the outer ear and one which is

surgically implanted into the inner

ear. In the portion behind the outer

ear, a microphone is used to pick up

sounds and send them to a speech

processor. Once processed, he sound

is transfered to a transmitter which

convens the sounds into an electrical

is transmitted to an electrode array

within the inner ear which stimulates the

auditory nerve, sending the message

to the brain. The sound from a cochlear

implant may not seem clear at first, but

with practice users can hear speech and

environmental sounds in a normal way.

Healthcare interventions are often measured by their ability to improve an individual's quality of life. Quality of Ife is measured as a health utility score. Commonly, three questionnaires are used to assess a person's health utillty score. One questionnaire in particular (the HUl mark 3) is used as a means individuals with hearing loss, fife in cost-effective treatments are. The utility

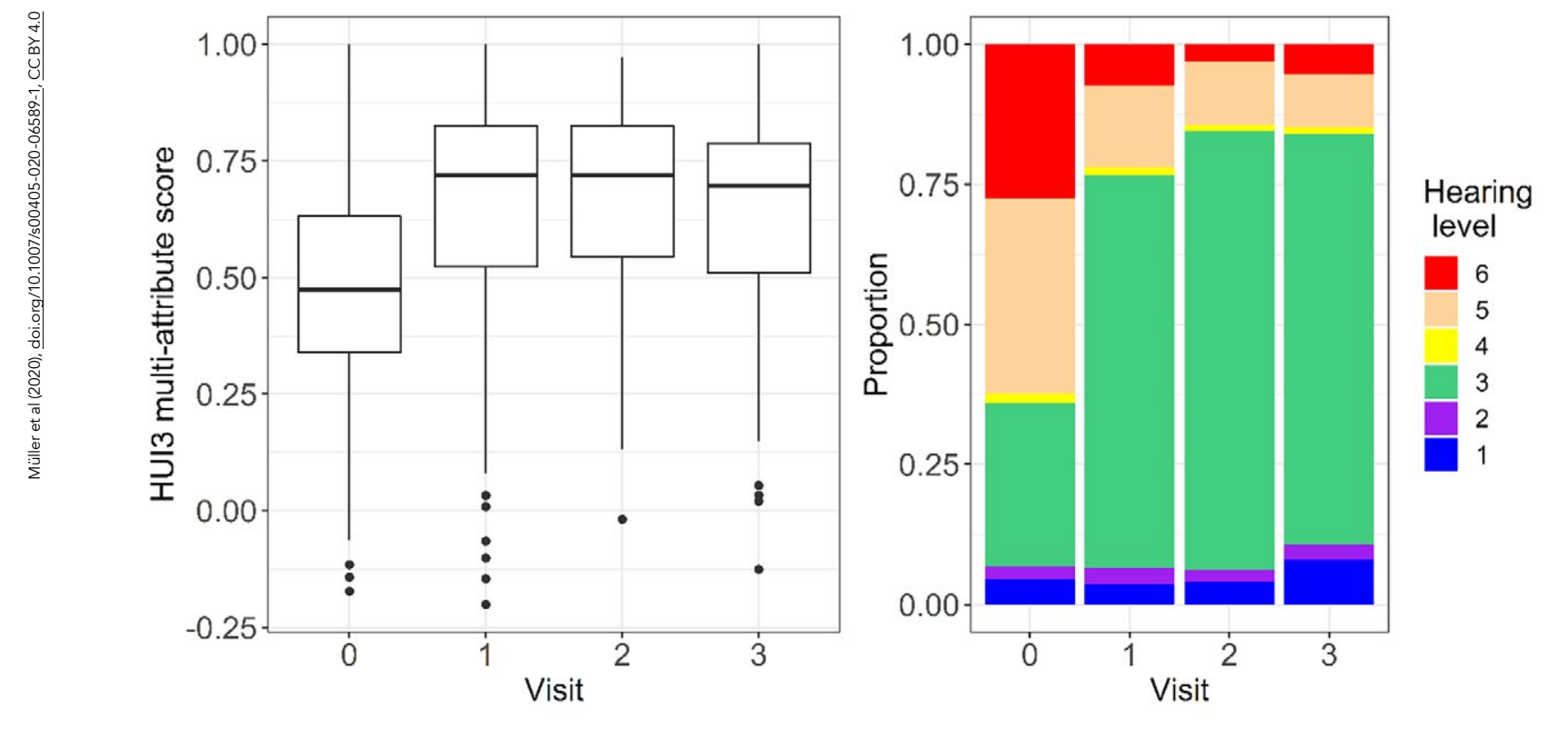

HUI3 multi-attribute and hearing scores at baseline and at one, two and three years
hear without a hearing aid) while level 6 indicates the total inability to hear (right).

score ranges from 0 to 1 , where 0.7 is disability and $>0.88$ is consideded mild or no disability. An improvement of 0.1 the improvement in quality of life is important because this is the ultimate goal of providing any medical treatmen patients for imp
lists are large.

A total of 175 cochlear implant recipients in South Africa were recruted for the study. Of these participants, 137 had a follow-up after the first year 97 after the second year and 75 after the third year. Out of these patients, In comparison to individuals who are $\quad 59 \%$ had a significant improvement in
struggling to understand speech even
their quality-of-life scores which was struggling to unders
with a hearing aid, the improvements in quality of life in individuals with a cochlear implant are higher. This is of particular

Individuals who have communication difficulties with strangers or when answering a phone call have the most to gain from this health intervention.

most severe hearing impairments in quality of life In the biggest gains was the inability to use the telephone prior to the implantation, which was then reversed by the implant, that was the biggest predictor of significant quality-of-life improvement. Telephon (the can seem a small thing which most other people take for granted. found it difficult to understand them were twice as likely to have countries such

where access to cochlear mplants is restricted due to long speech, even in more challenging

are likely to reap the most benefits may situations, when using the cochlear be prioritised for cochlear implants. However, little is known about the impact of co-morbidities prior to a cochlear implant. Such co-morbidities ears), dizziness, and depression.

\section{THE STUDY}

Paula Greenham and her co-authors aim to provide clinically relevant ginformation about potential health gains of cochlear implants. In particu chey aim to provide guidance for implant. Cochlear implantation improved quality of life and reduced the hearing loss. However, a smal improvement in hearing did not always result in an improvement in the qualityof-life measure.

WHAT ARE THE PREDICTORS FOR THE GREATEST IMPROVEMENT? It was found that age, sex, or duration of deaf noss had no impact on qualityof-life gains. Instead, the researchers individuals who reported being

to implant seemed to be twice as likely to gain significant improvement.

It must also be taken into account that the study can only include individuals and able to perform self-assessment. This means some biases do exist in the research. Nevertheless, this work represents an important guide for healthcare providers who need to make difficult should about which patients should be given priority for cochlear implantation. It appears that individuals who have communication difficulties phon call have the moswering a whis hall have the most to gain from 
